\title{
Factors Associated with Compliance in Submitting 24-Hour Urine Collections in an Underserved Community
}

\author{
Eric M. Ghiraldi, DO, Madhumitha Reddy, DO,' Tianyu Li, MS, \\ Andrew C. Lawler, and Justin I. Friedlander, MD ${ }^{1,4}$
}

\begin{abstract}
Purpose: Patients living in underserved areas do regularly express an interest in stone prevention; however, factors limiting participation, aside from obvious cost considerations, are largely unknown. To better understand factors associated with compliance with submitting 24-hour urine collections, we reviewed our patient experience at the kidney stone clinic at a hospital that provides care for an underserved urban community. Materials and Methods: A retrospective chart review of patients treated for kidney and/or ureteral stones between August 2014 and May 2016 was performed. Patient demographics, medical characteristics, stone factors, and compliance data were compiled into our data set. Patients were divided into two groups: those who did and did not submit the requested initial 24-hour urine collection. Analysis of factors related to compliance was performed using univariate analysis and multivariate logistic regression.

Results: A total of 193 patients met inclusion criteria for our study, 42.5\% (82/193) of whom submitted 24-hour urine samples. Of the 82 collections submitted, $34.1 \%$ (28/82) were considered inadequate by creatinine level. A second urine collection within 6 months was obtained in 14.0\% (27/193) of patients. Univariate analysis demonstrated that African American (AA) patients were less likely to submit an initial 24-hour urine collection than Caucasian patients (collected: $30.9 \%$ vs $51.8 \%$; $p<0.05$, respectively). Patients with a family history of kidney stones were more likely to submit an initial 24-hour urine collection than patients without a family history of kidney stones $(61.1 \%$ vs $38.2 \%, p<0.02$, respectively). On multivariate analysis, both factors remained significant predictors of compliance with submitting a 24-hour urine collection.

Conclusions: In our underserved patient population, AA patients were half as likely to submit a 24-hour urine collection than Caucasian patients, whereas patients with a positive family history of stones were more than twice as likely to submit than patients with no family history.
\end{abstract}

Keywords: nephrolithiasis, metabolic evaluation, compliance, underserved population

\section{Introduction}

T HE 24-HOUR urine collection is a main component of the medical management of kidney stone disease. Current American Urological Association (AUA) guidelines recommend one or two initial 24-hour urine collections in high-risk first-time stone formers, interested low-risk first-time stone formers, or recurrent stone formers, with a repeat 24-hour urine collection within 6 months of treatment. ${ }^{1}$ The success of kidney stone prevention programs in these groups is dependent on both patient- and physician-related factors, with patients needing motivation to participate and thus be compliant with recommendations, and physicians needing to regularly educate patients about the value of prevention even when the acute pain of a stone episode has resolved. Certainly, a strong patient-physician relationship will help further this goal, but at times may not be enough.

Underserved populations are infrequently studied in medicine, especially for benign, generally nonlife-threatening conditions such as kidney stone disease. Patients living in underserved areas do regularly express an interest in stone prevention; however, factors limiting participation, aside from obvious cost considerations, are largely unknown. To better understand factors associated with compliance with submitting 24-hour urine collections, we reviewed our patient experience at the kidney stone clinic at a hospital within our

${ }^{1}$ Department of Urology, Einstein Healthcare Network, Philadelphia, Pennsylvania.

${ }^{2}$ Biostatistics and Bioinformatics Facility, Fox Chase Cancer Center, Philadelphia, Pennsylvania.

${ }^{3}$ Philadelphia College of Osteopathic Medicine, Philadelphia, Pennsylvania.

${ }^{4}$ Division of Urologic Oncology and Urology, Fox Chase Cancer Center, Philadelphia, Pennsylvania. 
healthcare network that provides care for an underserved urban community.

\section{Materials and Methods}

After obtaining institutional review board approval, we performed a retrospective chart review of adult patients seen at the kidney stone clinic at Einstein Medical Center Philadelphia from August 2014 to May 2016. We included data from first-time stone formers as well as recurrent stone formers who had not had a prior metabolic evaluation. Patients were excluded from the study if they were under observation and/or had not undergone surgery for stones during this time period, or if they did not have sufficient follow-up. Patients were identified through query of the medical record.

The practice pattern at this clinic was as follows: patients were asked to submit a single 24-hour urine collection at the time of initial metabolic evaluation. Patients requiring any intervention (dietary and/or medical) based on 24-hour urine findings were asked to do a second collection within 6 months of the first collection, and again 6 months later. Further collections were then based on metabolic condition. The faculty made the decision for metabolic work-up. Collection instruction was provided by faculty, and for all non-English-speaking patients, translators were present per hospital protocol. Spanishspeaking patients were given kits with instructions in Spanish. Less than $5 \%$ of patients were non-English or non-Spanish speaking as primary language. Twenty-four-hour urine kits were mailed to the patient by Litholink ${ }^{\circledR}$ upon submission of required paperwork by office staff. All 24-hour urinalyses were processed by Litholink. A collection was deemed improper if it fell outside the normal gender-specific range of daily creatinine excretion (creatinine [Cr]/24 hour: males 20$25 \mathrm{mg} / \mathrm{kg}$, females $15-20 \mathrm{mg} / \mathrm{kg}$ ).

Patient demographics recorded included patient age, gender, race/ethnicity, body mass index (BMI), and insurance status (Medicaid/Medicare vs private insurance). Pertinent medical history recorded included information on stone-related medical comorbidities (diabetes mellitus, gout, inflammatory bowel disease, etc.), stone former status (first-time vs recurrent), and family history of kidney stones. Stone composition was recorded when available. Data were also recorded for compliance with recommended follow-up imaging after surgery.

Patients were divided into two groups: those who did and did not submit the initial requested 24-hour urine collection. Univariate analysis of the differences in demographics, medical conditions, and stone characteristics between groups was performed using Wilcoxon sign test for continuous variables and Pearson chi square test for categorical variables. Multivariate analysis of factors affecting compliance with submitting the initial 24-hour urine collection was performed using logistic regression. All statistical analyses were performed using SAS version 9.3 (Cary, North Carolina). A $p<0.05$ was considered to indicate statistical significance.

\section{Results}

After review, 193 patients were included in the study. Median age of patients in the overall study cohort was 50 years (range 18-85), with slight predominance in female gender $54.9 \%$, and median BMI was $28.4 \mathrm{~kg} / \mathrm{m}^{2}$ (range $17-$ 60). The median number of stones treated per patient was 2 (range 1-15). The patient population was predominantly
Table 1. Patient Demographics AND STONE CharaCteristics

\begin{tabular}{|c|c|}
\hline $\begin{array}{l}\text { Age in years } \\
\text { BMI, } \mathrm{kg} / \mathrm{m}^{2} \\
\text { Number of stones }\end{array}$ & $\begin{aligned} 50 & (18-85) \\
28.4 & (17-60) \\
2 & (1-15)\end{aligned}$ \\
\hline $\begin{array}{l}\text { Gender } \\
\text { Female } \\
\text { Male }\end{array}$ & $\begin{array}{l}55 \%(106) \\
45 \%(87)\end{array}$ \\
\hline $\begin{array}{l}\text { Insurance } \\
\text { Medicaid/Medicare } \\
\text { Private }\end{array}$ & $\begin{array}{l}50.3 \%(97) \\
49.7 \%(96)\end{array}$ \\
\hline $\begin{array}{l}\text { Race } \\
\text { African American } \\
\text { Caucasian } \\
\text { Other }\end{array}$ & $\begin{array}{r}35 \%(67) \\
29.5 \%(56) \\
35.5 \%(67)\end{array}$ \\
\hline $\begin{array}{l}\text { Diabetes } \\
\text { Yes } \\
\text { No }\end{array}$ & $\begin{array}{l}15 \%(29) \\
85 \%(164)\end{array}$ \\
\hline $\begin{array}{l}\text { Stone-related comorbiditie } \\
\text { Yes } \\
\text { No }\end{array}$ & $\begin{array}{l}45.8 \%(88) \\
54.2 \%(104)\end{array}$ \\
\hline $\begin{array}{l}\text { Family history of stones } \\
\text { Yes } \\
\text { No }\end{array}$ & $\begin{array}{l}18.8 \%(36) \\
81.2 \%(156)\end{array}$ \\
\hline $\begin{array}{l}\text { Stone history } \\
\text { First time stone former } \\
\text { Recurrent stone former }\end{array}$ & $\begin{array}{l}56.3 \%(107) \\
43.7 \%(83)\end{array}$ \\
\hline $\begin{array}{l}\text { Staghorn calculus } \\
\text { Yes } \\
\text { No }\end{array}$ & $\begin{array}{r}8.8 \%(17) \\
91.2 \%(176)\end{array}$ \\
\hline $\begin{array}{l}\text { Stone composition } \\
\text { Calcium oxalate } \\
\text { Noncalcium oxalate } \\
\text { Unknown }\end{array}$ & $\begin{array}{l}57 \%(110) \\
17.6 \%(34) \\
25.4 \%(49)\end{array}$ \\
\hline
\end{tabular}

All continuous variables reported as median (range); all categorical variables reported as percentage (number).

$\mathrm{BMI}=$ body mass index; $\mathrm{DM}=$ diabetes mellitus

Table 2. Results of Compliance WITH RECOMMENDED CARE

\begin{tabular}{ll}
\hline & $\begin{array}{c}\% \text { of total } \\
(\text { No. of patients) }\end{array}$ \\
\hline $\begin{array}{l}\text { Completed post-treatment imaging } \\
\text { Yes }\end{array}$ & $59.6 \%(115)$ \\
No & $40.4 \%(78)$ \\
Completed 24-hour urine & \\
$\quad$ Yes & $42.5 \%(82)$ \\
$\quad$ No & $57.5 \%(111)$ \\
Completed imaging and 24-hour & $32.6 \%(63)$ \\
$\quad$ urine collection & \\
Completed imaging or 24-hour & $69.4 \%(134)$ \\
$\quad$ urine collection & $34.1 \%(28)$ \\
Improper urine collection & $14.0 \%(27)$ \\
Completed a second 24-hour & urine collection \\
Completed a third 24-hour & $6.2 \%(12)$ \\
$\quad$ urine collection & \\
\hline
\end{tabular}


Table 3. Univariate Analysis of Factors Related to 24-Hour Urine Submission

\begin{tabular}{|c|c|c|c|}
\hline Variable & $\begin{array}{l}\text { Submitted } \\
\text { 24-hour urine } \\
\text { collection }\end{array}$ & $\begin{array}{c}\text { Did not } \\
\text { submit 24-hour } \\
\text { urine collection }\end{array}$ & $\mathrm{p}$ \\
\hline Age in years & $52.5(18-85)$ & $46(19-83)$ & 0.13 \\
\hline $\mathrm{BMI}, \mathrm{kg} / \mathrm{m}^{2}$ & $29.0(17-60)$ & $28(17-52)$ & 0.07 \\
\hline Number of stones & $2(1-15)$ & $2(1-10)$ & 0.79 \\
\hline \multicolumn{4}{|l|}{ Gender } \\
\hline Female & $37.7 \%(40)$ & $62.3 \%(66)$ & \multirow[t]{2}{*}{0.14} \\
\hline Male & $48.3 \%(42)$ & $51.7 \%(45)$ & \\
\hline \multicolumn{4}{|l|}{ Insurance } \\
\hline $\begin{array}{l}\text { Medicaid/ } \\
\text { Medicare }\end{array}$ & $37.1 \%(36)$ & $69.1 \%(61)$ & \multirow[t]{2}{*}{0.13} \\
\hline Private & $47.9 \%(46)$ & $52.1 \%(50)$ & \\
\hline \multicolumn{4}{|l|}{ Race } \\
\hline $\begin{array}{l}\text { African } \\
\text { American }\end{array}$ & $30.9 \%(21)$ & $69.1 \%(47)$ & \multirow[t]{3}{*}{$<0.05$} \\
\hline Caucasian & $51.8 \%(29)$ & $48.2 \%(27)$ & \\
\hline Other & $45.6 \%(31)$ & $54.4 \%(37)$ & \\
\hline \multicolumn{4}{|l|}{ Diabetes } \\
\hline Yes & $55.2 \%(16)$ & $44.8 \%(13)$ & \multirow[t]{2}{*}{0.13} \\
\hline No & $40.2 \%(66)$ & $59.8 \%(98)$ & \\
\hline \multicolumn{4}{|c|}{ Stone-related comorbidities (including DM) } \\
\hline Yes & $47.7 \%(42)$ & $52.3 \%(40)$ & \multirow[t]{2}{*}{0.18} \\
\hline No & $38.1 \%(46)$ & $61.9 \%(65)$ & \\
\hline \multicolumn{4}{|c|}{ Family history of stones } \\
\hline Yes & $61.1 \%(22)$ & $38.9 \%(14)$ & \multirow[t]{2}{*}{$<0.02$} \\
\hline No & $38.2 \%(60)$ & $61.8 \%(97)$ & \\
\hline \multicolumn{4}{|l|}{ Stone history } \\
\hline $\begin{array}{l}\text { First time stone } \\
\text { former }\end{array}$ & $41.1 \%(44)$ & $58.8 \%(63)$ & \multirow[t]{2}{*}{0.63} \\
\hline $\begin{array}{l}\text { Recurrent stone } \\
\text { former }\end{array}$ & $44.5 \%(37)$ & $55.4 \%(46)$ & \\
\hline \multicolumn{4}{|l|}{ Staghorn calculus } \\
\hline Yes & $35.3 \%(6)$ & $64.7 \%(11)$ & \multirow[t]{2}{*}{0.53} \\
\hline No & $43.2 \%(76)$ & $56.8 \%(100)$ & \\
\hline \multicolumn{4}{|c|}{ Stone composition } \\
\hline Calcium oxalate & $43.6 \%(48)$ & $56.4 \%(62)$ & \multirow[t]{2}{*}{0.71} \\
\hline $\begin{array}{l}\text { Noncalcium } \\
\text { oxalate }\end{array}$ & $41.0 \%(34)$ & $59.0 \%(49)$ & \\
\hline
\end{tabular}

All continuous variables reported as median (range); all categorical variables reported as percentage (number).

African American (AA) (AA 35\%, Caucasian 29.5\%, and other $35.5 \%$ ). Patient populations who fell under the category of "other" included Hispanic, Asian/Pacific, Indian, and Middle Eastern, with most patients within this category being Hispanic (72\%). Medicaid insured $47.2 \%$ of the patient

Table 4. Multivariate Logistic Regression Predicting Completing 24-Hour Urine Collection

\begin{tabular}{lcccc}
\hline & \multicolumn{4}{c}{$95 \%$ confidence } \\
& OR & limits & $\mathrm{p}$ \\
\hline Age at visit & 1.019 & 0.999 & 1.039 & 0.10 \\
BMI & 1.029 & 0.985 & 1.074 & 0.20 \\
Race (AA $v s$ white) & 0.459 & 0.213 & 0.988 & $<0.05$ \\
Race (other $v s$ white) & 1 & 0.472 & 2.122 & 1 \\
Family history (yes or no) & 2.406 & 1.105 & 5.239 & $<0.03$ \\
\hline
\end{tabular}

$\mathrm{AA}=$ African American. cohort, whereas $52.8 \%$ were privately insured or insured by Medicare. A positive family history of kidney stones was identified in only $18.8 \%$ of the patient population and $43.7 \%$ of the patient population were recurrent stone formers. Demographic data can be seen in Table 1.

Of the 193 patients who met inclusion criteria, 82 (42.5\%) submitted an initial 24-hour urine sample. The majority of patients were found to have calcium oxalate stones upon composition analysis (75.4\%). Rates of 24-hour urine abnormalities identified among patients who submitted initial 24-hour urine collections were low urine volume (64\%), hypocitraturia $(35 \%)$, hyperoxaluria $(34 \%)$, hypernatriuria (29\%), and hypercalcuria (12\%). Of the 82 collected 24 -hour urine samples, $28(34.1 \%)$ were deemed improper collections by creatinine. Of the 82 patients who submitted the initial 24-hour urine collection (adequate or inadequate), only 27 (32.9\%) submitted a second 24-hour urine collection, corresponding to $14.0 \%$ of the overall cohort. Twelve of the 27 patients $(44.4 \%)$ who submitted a second 24-hour urine sample went on to submit a third 24-hour urine sample, corresponding to $6.2 \%$ of the entire cohort. One-hundred thirty-four of the 193 patients $(69.4 \%)$ had either postoperative imaging or 24-hour urine collection, 115 patients (59.6\%) obtained postoperative imaging alone without collecting a 24-hour urine sample, and 63 patients $(32.6 \%)$ had both postoperative imaging and 24-hour urine collection. Compliance data are shown in Table 2.

Outcomes of univariate analysis are shown in Table 3. Results showed that AA patients were less likely to submit an initial 24-hour urine collection than Caucasian patients (collected: $30.9 \%$ vs $51.8 \%$; $p<0.05$, respectively). Patients with a family history of kidney stones were more likely to submit an initial 24-hour urine collection than patients without a family history of kidney stones $(61.1 \%$ vs $38.2 \%$, $p<0.02$, respectively). None of the other parameters studied were significantly different between groups.

On multivariate analysis, both factors remained significant predictors of compliance with submitting a 24-hour urine collection (Table 4). AA patients were less likely than Caucasian patients to submit a 24-hour urine sample (odds ratio [OR] 0.459, confidence interval [95\% CI] 0.213, 0.988, $p<0.05$ ), whereas patients with a family history of kidney stones also remained more likely to submit a 24-hour urine sample (OR 2.406, 95\% CI 1.105, 5.239, $p<0.03)$. No other variable tested was found to be statistically significant.

\section{Discussion}

Since the publication of the landmark Heckler Report in 1985, it has been well documented that patients living in underserved medical communities have less access to care and poorer medical outcomes. ${ }^{2}$ This patient group is not frequently reported on in the stone literature, and is also not routinely captured in large administrative database studies of privately insured patients. Recently, it has been shown that patients with low annual household income are at significantly increased risk of reporting kidney stones than higher income groups. ${ }^{3}$ One of the hospitals in our network, Einstein Healthcare Center Philadelphia, serves a community with an estimated median annual household income of $\$ 28,622$ and $31.8 \%$ of individuals living below the United States poverty level. ${ }^{4}$ Having a stone clinic in this setting offered us the 
unique opportunity to study an often overlooked population with regard to compliance with care for kidney stone disease.

Our study aimed to both document rates of compliance with follow-up and identify patient- and stone-related factors associated with submission of 24-hour urine collections. Overall, our initial 24-hour submission rate was 42.5\% (82/ 193), which is higher than rates described in the literature. This may be related to having only a single collection as the initial work-up because of concern about two collections being burden for this patient population. Using a commercially available database of insured patients, Milose et al. identified 28,836 stone formers at high risk for recurrence. ${ }^{5}$ The prevalence of 24-hour urine collection increased from $7.0 \%$ to $7.9 \%$ over the study period (2002-2006), with an overall prevalence of $7.4 \% .^{5}$ Despite our initial success, we did note a fair degree of attrition over the study period, with only $14.0 \%$ of those submitting the initial collection providing a subsequent sample. We believe our result to be more reflective of compliance than practice patterns as we had a strict protocol and one endourologist staffing a stone-specific clinic.

The only factors found to be predictive of 24-hour urine collection submission on both univariate and multivariate analyses were race and family history. AA patients were half as likely to submit a 24-hour urine collection than Caucasian patients. It has been shown that AA patients experience higher levels of medical mistrust and experience poorer communication with healthcare providers than other racial groups, ${ }^{6}$ and these facts may explain our findings and must be considered and addressed when counseling patients. Patients with a positive family history of stones were more than twice as likely to submit a 24-hour urine collection than patients with no family history. We suspect that higher compliance for those with family history of stones is likely related to reinforcement from trusted family members with a shared experience.

Other studies have investigated demographic factors associated with compliance with stone treatment. In a retrospective review of 447 patients treated at a single metabolic stone clinic, Sninsky and colleagues identified age, gender, and socioeconomic status to be specific risk factors for poor initial follow-up and 24-hour urine collection compliance. ${ }^{7}$ Younger age was associated with the highest rate of "no shows" (29.2\%), lowest percentage of clinic appointments attended $(40.9 \%)$, and the lowest percentage of 24-hour urine collections completed $(50.7 \%){ }^{7}$ Poverty-stricken areas were divided based on the mean poverty rate per area code. Prevalence of "no shows" for scheduled appointments showed a direct correlation for patients living in poorer areas. Within our cohort, patients between the ages of 18 and 30 years demonstrated the lowest initial 24-hour urine collection rate $(11 / 33,33 \%)$, whereas older patients between the ages of 41 and 50, 51 and 60, and 61 and 70 had 24-hour urine collection rates of $44 \%, 41 \%, 51 \%$, respectively. Despite these differences in compliance, no statistical significance was found across groups $(p=0.13)$, possibly because of our limited sample size. The literature has shown that the rate of recurrence for urinary tract stones is $\sim 50 \%$ at 5 years and $\sim 75 \%$ at 20 years. $^{3,8}$ For this reason, younger first-time stone formers must be encouraged to follow up to prevent likely visits to the emergency room as well as other sequela from largely preventable future stone episodes.

In addition, lower socioeconomic status has been associated with factors placing patients in the high-risk category for stone recurrence. A retrospective review of 435 patients from two metabolic stone clinics identified that poverty and decreased education level were significantly associated with increased urine calcium levels. 9 Poor diet and sedentary lifestyle were thought to be a major contributor to these findings. Decreased education level was also associated with increased supersaturation of calcium oxalate and calcium phosphate. $^{9}$

The use of 24-hour urine collections is also strongly influenced by provider practice patterns. In a recent questionnaire distributed to members of the endourological society, 12 questions were used to assess contemporary attitudes of specialists with regard to metabolic work-up for stone disease. ${ }^{10}$ Of 124 responders, $44 \%$ reported collecting a 24-hour urine sample in all recurrent stone formers, 32\% reported collecting in first-time stone formers with risk factors, $13 \%$ reported collecting in recurrent stone formers with risk factors, $5 \%$ reported collecting in all first-time stone formers, and $6 \%$ reported collecting in all clinical scenarios. ${ }^{10}$ This study exposed wide variations for the metabolic work-up of stone disease, which may explain low rates of 24-hour urine utilization seen elsewhere.

Studies have also looked at provider compliance with obtaining repeat 24-hour urine studies. The AUA guidelines recommend a repeat 24-hour urine study within 6 months of treatment to assess response to treatment. ${ }^{1}$ A retrospective review of Litholink data by Dauw et al. from 1995 to 2013 revealed that out of 208,125 patients with a metabolic abnormality identified, only 33,413 patients had repeat collection within 6 months $(6.23 \%) .{ }^{11}$ Younger patients and patients with lowsocioeconomic status were found to have lower rates of repeat testing. ${ }^{11}$ The study concluded that repeat 24-hour urine collection was uncommon even in patients with metabolic abnormalities; however, study design limited the ability to determine whether this was a function of patient compliance or failure of the provider. Our rate of repeat 24-hour urine collection was $14.0 \%$ (27/82). Our higher rate may reflect granular factors not able to be assessed in studies using administrative data.

Unfortunately it is all too common for 24-hour urine collections to be deemed inadequate, thus requiring repeating, which further risks noncompliance. Numerous studies have described rates of inadequate 24-hour urine collection. Inadequate urine collection is often classified either as an under collection or an over collection. This is commonly determined in practice by calculating the $24-$ hour $\mathrm{Cr} / \mathrm{kg}$ ratio (normal: males: $20-25 \mathrm{Cr} / \mathrm{kg}$, females: $15-20 \mathrm{Cr} / \mathrm{kg}$ ). ${ }^{12}$

Sawyer and coworkers performed a retrospective review of 381 stone formers. They found an inadequate 24-hour urine collection rate of $50.7 \%$. More importantly, they showed that a higher $\mathrm{Cr} / \mathrm{kg}$ ratio is associated with higher levels of urine calcium. ${ }^{13}$ They concluded that providers should be cautious of implementing unnecessary treatment for urine parameters that are abnormal with over-collected samples. In another retrospective single-institution review of 1502 patients, McGuire and coworkers found the identical inadequate 24 -hour urine collection rate of $50.7 \% .{ }^{14}$ In their study, they found women to be $50 \%$ more likely to submit inadequate samples than men. In addition, patients with diabetes were more likely to submit adequate samples, whereas patients on vitamin D supplementation and those with a manual labor occupation were less likely to submit adequate samples. ${ }^{14}$ In our study, no variables were found to be statistically 
significant in predicting inadequate urine samples. Our rate of inadequate 24-hour urine collection was only $34.1 \%(28 / 82)$, much lower than that of other studies. This may be because of provided related factors that were not fully assessed, such as time spent educating patients.

Our study has a number of limitations, including retrospective design with its inherent biases, small sample size, and limited follow-up period. In addition, our database was limited to specific patient demographics and stone characteristics, and absence of other factors important to patient compliance may have led to different results. Nonetheless, it is one of a handful of studies evaluating management of kidney stone disease in an underserved population.

\section{Conclusions}

In our underserved patient population, AA patients were half as likely to submit a 24-hour urine collection than Caucasian patients, whereas patients with a positive family history of stones were more than twice as likely to submit than patients with no family history. Addressing these findings will help improve our management of kidney stone disease in this patient population.

\section{Acknowledgment}

We thank Dr. Alexandra H. Weiss for her assistance with this article.

\section{Author Disclosure Statement}

Dr. J.I.F is a consultant for Retrophin; however, his association with this entity had no relationship with any aspect of creation or production of this article. None of the other authors have any disclosures to report.

\section{References}

1. Pearle MS, Goldfarb DS, Assimos DG, et al. Medical management of kidney stones: AUA guideline. J Urol 2014; 192:316-324.

2. Liao Y, Bang D, Cosgrove S, et al. Surveillance of health status in minority communities-Racial and Ethnic Approaches to Community Health Across the U.S. (REACH U.S.) Risk Factor Survey, United States, 2009. MMWR Surveill Summ 2011;60:1-44.

3. Scales CD, Smith AC, Hanley JM, et al. Prevalence of kidney stones in the United States. Eur Urol 2012;62:160-165.

4. United States Census Bureau, 2010-2014 American Community Survey 5-year Estimates. Available at: http:// factfinder.census.gov/faces/nav/jsf/pages/community_facts. xhtml Accessed August 15, 2016.
5. Milose JC, Kaufman SR, Hollenbeck BK, et al. Prevalence of 24-hour urine collection in high risk stone formers. J Urol 2014;191:376-380.

6. Cuevas AG, O'Brien K, Saha S. African American experiences in healthcare: "I always feel like I'm getting skipped over". Health Psychol 2016;35:987-995.

7. Sninsky BC, Nakada SY, Penniston KL. Does socioeconomic status, age, or gender influence appointment attendance and completion of 24 hour urine collections. Urology 2015;85:568-573.

8. Worcester EM, Coe FL. Clinical practice. Calcium kidney stones. N Engl J Med 2010;363:954-963.

9. Eisner BH, Sheth S, Dretler SP, et al. Effect of socioeconomic status on 24 hour urine composition in patients with nephrolithiasis. Urology 2012;80:43-47.

10. McGuire BB, Matulewicz RS, Zuccarino-Crowe R, et al. Contemporary attitudes and practice patterns of North American urologists in investigating stone forming patientsA survey of endourological society members. J Endourol 2016;30:460-464.

11. Dauw CA, Alruwaily AF, Bierlein MJ, et al. Provider variation in the quality of metabolic stone management. J Urol 2015;193:885-890.

12. Reilly RF, Perazella MA. Chronic kidney disease. In: Nephrology in 30 Days. New York: McGraw Hill Medical Publishing, 2005, pp. 251-274.

13. Sawyer MD, Dietrich MS, Pickens RB, et al. Adequate or not? A comparison of 24 hour urine studies for renal stone prevention by creatinine to weight ratio. J Endourol 2013; 27:366-369.

14. McGuire BB, Bhanji Y, Sharma V, et al. Predicting patients with inadequate 24- or 48-hour urine collections at time of metabolic stone evaluation. J Endourol 2015;29: 730-735.

\section{Address correspondence to: Justin I. Friedlander, MD Department of Urology Einstein Healthcare Network 1200 Tabor Road, 3rd Floor Philadelphia, PA 19141 \\ E-mail: friedlaj@einstein.edu}
Abbreviations Used
$\mathrm{AA}=$ African American
$\mathrm{BMI}=$ body mass index
$\mathrm{CI}=$ confidence interval
$\mathrm{Cr}=$ Creatinine
$\mathrm{OR}=$ odds ratio 